\title{
L'ATRIBUCIÓ DE SENTIT A L'APRENENTATGE I L'ENSENYANÇA. PARLEM DE SENTIMENTS, EMOCIONS I AFECTES A L'AULA
}

\author{
Enric Valls Giménez. Àrea de Psicologia Evolutiva i de l'Educació. URV
}

\begin{abstract}
L'experiència afectiva i relacional impregna del tot les interaccions entre alumnes, continguts i professor quan duen a terme processos conjunts d'aprenentatge i ensenyança. La interacció educativa, en qualsevol nivell de l'ensenyança, no és emocionalment neutra. Així -mirantho des del vessant optimista-, és evident que professor i estudiants es generen mútuament afectes, aproximacions, sentiments i emocions. El mateix passa en la relació entre els estudiants i el contingut d'aprenentatge: el viuen com a interessant, fàcil, profitós; o entre el professor i la matèria que ensenya, perquè ho fa de forma molt personal, sentida, i se li nota que ho viu emocionalment...

Però la influència dels factors afectius i relacionals sobre l'aprenentatge ha estat objecte de menor interès en la investigació educativa si es compara, per exemple, amb l'estudi de la contribució de les característiques cognitives. En tot cas, els factors afectius i relacionals han estat més analitzats com a influents en la creació del clima d'aula, de les dinàmiques de grup, per explicar els processos interactius que hi tenen lloc, com a element important en les definicions de bon professor o d'alumne ideal, però menys en la mesura que afecten directament els aprenentatges. Sigui com sigui, l'evidència clara que els factors afectius també condicionen els rendiments $i$ resultats dels aprenentatges escolars -a parvulari i a la universitat!- ha fet que la recerca els hagués de considerar d'alguna manera, sovint, però, diluint-los en temes com la motivació, els estils cognitius, la intel-ligència emocional o altres, i molt freqüentment amb gran confusió terminològica o des de perspectives bastant ateòriques o poc integradores.
\end{abstract}

La concepció constructivista de l'aprenentatge i ensenyança, en canvi, reclama el reconeixement exprés del pes de factors afectius i relacionals per explicar l'aprenentatge, incloent el seu estudi en el que s'anomena trobar sentit a l'aprenentatge. Des d'aquesta perspectiva, la trobada de sentit juntament amb la construcció del significat defineixen i orienten la naturalesa de l'aprenentatge; aprendre consisteix a assolir una comprensió més o menys completa d'allò que s'aprèn i, alhora, que l'estudiant se senti implicat personalment, hi trobi importància, ho reconegui com a valuós o funcional. És a dir, els coneixements que s'aprenen i el mateix procés d'aprenentatge suscitarien afecte, emoció, un nou sentit, i no només significació, comprensió.

En el present article ens remetem a l'experiència duta a terme amb els trenta-set estudiants de $2 n$ curs, promoció 2003-2006, d'Educació Infantil de l'Ensenyament de Mestre, amb motiu del treball en l'assignatura de Psicologia de l'Educació. Sense la seva gran implicació no hauria estat possible arribar a descripcions, anàlisis, interpretacions i propostes significatives sobre la influència de factors afectius i relacionals en la trobada de sentit als aprenentatges realitzats (informe final del projecte "L'ensenyament de la Psicologia de l'Educació des de la perspectiva de la convergència europea: una proposta basada en el treball de l'alumne i en l'ús de les noves tecnologies de la informació i la comunicació" Projecte MQD 00149, subvencionat pel Departament d'Universitats, Recerca i Societat de la Informació de la Generalitat de Catalunya. Barcelona, desembre de 2005).

\section{Parlar obertament d'afectes, sentiments i emocions a l'aula}

Si la consideració dels afectes i emocions no pot quedar al marge de l'explicació dels processos d'aprenentatge i ensenyança, ¿per què tan poca sistematització del tema fins ara?, ¿per què limitar formalment l'experiència d'aprendre només al cognitiu?, ¿per què no una planificació, realització i avaluació de l'aprenentatge i ensenyança que tingui en compte els factors afectius $i$ relacionals?, ¿per què sembla ben pertinent, per exemple, preguntar-li a l'estudiant si entén el que s'explica i, en canvi, sembla fora de lloc, infantilitzador, impropi, preguntar-li si li afecta o li agrada personalment allò que està aprenent?

$\mathrm{Hi}$ ha certa reticència, tant del professorat com de l'alumnat, a fer conscient i explícit l'afectiu i relacional com a factor de l'aprenentatge i l'ensenyança, exceptuant potser els temps de l'educació infantil i la primària. Dita 


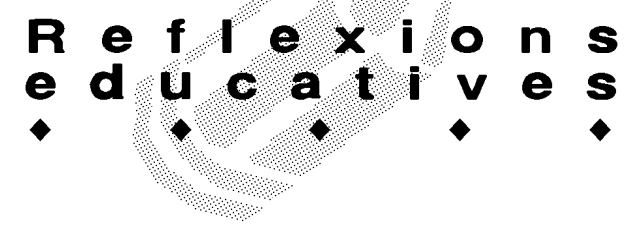

actitud es justifica en creences com que l'afectiu és difícil de controlar com a variable; que es tracta d'un fenomen psicològic molt personal i diferenciat entre les persones; que la seva contribució es limita, en tot cas, a crear, mantenir i potenciar un clima positiu que predisposi a l'aprenentatge, però que no hi incideix directament; altres vegades, la reticència es deu al fet que parlar explícitament de l'afectiu en l'ensenyança suscita entre professorat i estudiants certa vergonya, rebuig, sensacions ambigües.

Més enllà d'aquestes actituds i prevencions, la investigació psicològica sobre la relació entre trets individuals i aprenentatge destaca que mentre les característiques cognitives influirien bàsicament sobre la qualitat dels aprenentatges, les característiques afectives incidirien sobre la quantitat d'aquests condicionants, sobretot l'esforç o disposició de l'estudiant envers la tasca i la persistència o dedicació per dur-la a terme. El pes relatiu d'unes característiques i altres definiria el compromís de l'estudiant en l'aprenentatge, i aquest compromís, al seu torn, determinaria el resultat del procés d'aprenentatge.

Com s'ha dit, des de la concepció constructivista fem servir les nocions de sentit i de trobada o atribució de sentit per referir-nos a la incidència de la dimensió afectiva, emocional i relacional en els processos de construcció del coneixement. Aquesta influència explica, en gran mesura, la disposició, la dedicació, els interessos, els desigs, els propòsits, les expectatives, la vàlua atribuïda a allò que s'aprèn, uns aspectes a considerar com a claus del mateix procés de construcció del coneixement.

Des de la mateixa concepció s'entén també que la definitiva influència d'aquests components està mediatitzada per la naturalesa dels continguts objecte d'aprenentatge i per les característiques del context instruccional en el qual tenen lloc els processos d'aprenentatge i ensenyança, d'entre les quals destaquen, particularment, les actuacions del professor i les interaccions entre aquest i l'alumnat. Per això el que referirem de l'experiència mantinguda en el seguiment de l'assignatura de Psicologia de l'Educació consistirà no tant a reconèixer indicadors de vida afectiva i relacional a l'aula -cosa òbvia-, sinó a evidenciar indicadors de com a estudiants i professor, a través del disseny del treball de l'assignatura i de les seves intervencions, s'han implicat conjuntament en la construcció i manteniment de la dinàmica afectiva i relacional que promogui aprenentatges a l'aula.

\section{Condicions que determinen la possibilitat d'atribuir sentit personal a l'aprenentatge}

Hem constatat en l'experiència realitzada, d'acord amb el que assenyala la recerca sobre la qüestió, que hi ha unes condicions reconegudes com a més decisives perquè els estudiants s'impliquin afectivament en l'aprenentatge i hi descobreixin un sentit personal: es tracta que trobin interessant el treball escolar i se'l representin convenientment. En parlem a continuació.

1. Els continguts d'aprenentatge i les activitats que es proposen per aprendre'ls han de connectar amb els interessos personals dels estudiants.

Amb estudiants més petits no esdevé gaire difícil identificar els principals interessos que es poden trobar amb l'aprenentatge. La majoria són immediats, associats, per exemple, a la satisfacció que dóna acabar la feina, rebre elogis o reconeixement, assolir algun repte, solucionar alguna necessitat immediata, trobar respostes a preguntes. En la vida universitària a aquests interessos -que hi segueixen estant, sens dubte!-s'afegeixen altres més diferits, com els associats a l'activitat professional per a la qual es preparen els estudiants. És cert que les històries personals de necessitats sentides i satisfetes $\mathrm{i}$ de valors posats en les tasques escolars fan que els interessos acadèmics pressuposats -més immediats, o més "professionals"- no siguin experimentats igual per tots i cadascun dels estudiants.

L'experiència realitzada ha demostrat, per una banda, que no esdevé difícil trobar molts interessos compartits entre el conjunt dels estudiants als quals es puguin referir continguts i activitats d'aprenentatge. Així, a diferència d'altres, una matèria com la Psicologia de l'Educació, on s'expliquen els canvis psicològics que s'indueixen en les situacions educatives i quins són els factors intrapersonals i interpersonals més decisius que provoquen aquests canvis, té molt de guanyat, d'entrada, com a tema interessant per a futurs mestres; per tant, més que dels continguts en si, del que calia tenir més cura era de les activitats d'aprenentatge d'aquests continguts, de manera que els estudiants les trobessin interessants.

En el pla docent de l'assignatura es proposaren fins a setze activitats d'aprenentatge -set a realitzar individualment, i nou en equip- i es demanà expressament en les fitxes d'identificació de l'activitat (una fitxa per a cada activitat) que l'estudiant, un cop realitzada l'activitat, donés valor al producte presentat i al corresponent procés d'elaboració. A partir d'aquestes informacions i d'altres extretes d'exercicis d'autoavaluació, hem pogut identificar tres grans grups d'interessos que els estudiants manifesten associats a la realització de les activitats d'aprenentatge proposades:

Un primer grup d'interessos gira entorn de l'experiència immediata de satisfacció que es pot trobar a fer les activitats proposades: obtenir productes, constatar guany personal, crear coneixement, haver dut a terme 


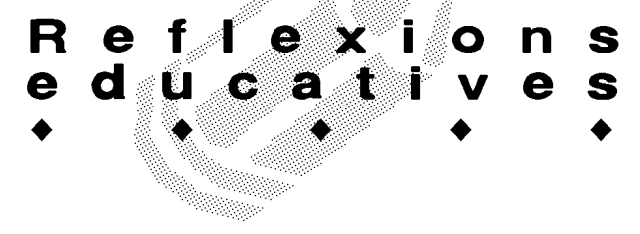

un procés més o menys laboriós, tastar autonomia o cooperació (en tasques d'equip), posar en pràctica destreses cognitives d'ordre superior (comprensió, diferenciació, anàlisi, transferència).

Encara que totes les activitats d'aprenentatge proposades podien, en principi, connectar amb interessos d'aquest primer grup, les més esmentades foren les següents:

- Descoberta i sistematització de les característiques generals dels processos de construcció dels significats, a partir d'analogies.

- Identificació de les característiques més essencials de la concepció constructivista de l'aprenentatge i ensenyança recollint-les en un document per a la seva defensa pública.

- Reconeixement de la pròpia activitat cognitiva a l'hora de l'estudi personal.

- Crítica de formes simples d'expressar-se sobre les relacions entre característiques individuals de l'alumnat i rendiment escolar.

- Elaboració d'un conjunt de factors psicològics de naturalesa personal, considerats determinants del rendiment escolar no explicitats en un text.

- Estudi específic del paper que juguen els coneixements previs, o la intel-ligència, o els hàbits de treball en els rendiments escolars.

- Repàs del que significa atribuir un sentit personal a allò que s'aprèn i de quines són les causes i condicions principals que l'afavoreixen.

- Judici de fins a quin punt el treball d'equip dut a terme en l'assignatura ha estat un treball cooperatiu.

Un segon grup de raons per les quals les activitats eren considerades interessants ha girat entorn de la importància 0 utilitat que l'estudiant pensa que poden tenir les tasques d'aprenentatge programades de cara al seu desenvolupament professional, en aquest cas com a futurs mestres d'educació infantil. Les activitats d'aprenentatge més relacionades amb aquests interessos foren les següents:

- Comparació i diferenciació entre pràctiques educatives, centrant-se en aquelles que són més específiques de les pràctiques educatives escolars i familiars.

- Reflexió sobre la pertinença per a l'escola infantil de les recomanacions o principis d'actuació constructivistes.

- Comparació entre diversos materials habituals a les aules (textos, materials didàctics, fitxes de treball, etc.) per poder valorar-los com a materials més o menys potencialment significatius.

- Plantejament d' un decàleg d'actuacions del do- cent a parvulari encaminades a facilitar la trobada de sentit a tot allò que fa un infant.

- Observació, descripció i anàlisi de situacions interactives espontànies entre infants.

- Reconeixement de la dinàmica d'aula que es genera en una escola i del paper que hi juga el mestre en la seva configuració.

- Identificació d'estratègies i recursos discursius propis de la parla educacional que ha pogut fer servir el professor dins de l'aula per ajudar a la construcció del coneixement.

Encara es podria identificar un altre grup d'interessos relacionats amb el maneig de determinats instruments que formaven part de l'entramat metodològic del disseny de l'assignatura: fer recerca de dades i informacions, l'escriptura del diari personal, consultes a través d'internet, carpetes ben guarnides, pulcritud en la realització de les fitxes i activitats, treball en la plataforma Edustance (que era la utilitzada en el moment de dur a terme l'experiència), o altres.

Però l'experiència ha servit també per recordar-nos que l'emocional, l'afectiu, el que interessa personalment i mou a l'acció és, en gran manera, un factor de diversitat intrapersonal i interpersonal prou important com per oblidar-ho a les aules. L'experiència ha servit per alertarnos que, més enllà de preparar i presentar al grup continguts $i$ activitats que podien suscitar interès de manera natural i fàcil, la intervenció del professor ha de dirigir-se particularment cap a aquells estudiants que no el troben tan fàcilment, per revifar-lo, per recrear una necessitat, per fer veure interessant el contingut $i$ l'activitat d'aprenentatge.

D'acord amb el que aporta la investigació psicològica, hem constatat que les principals reticències dels estudiants a mostrar interès particular envers algunes activitats estaven estretament relacionades amb elements del seu autoconcepte i de la seva autoestima. D'entre les mencionades de manera més sincera i clara destaquem les tres següents: la percepció que la manca de temps suficient per fer les activitats originava produccions incompletes 0 superficials i es malmetia, en conseqüència, una imatge positiva personal; certa sensació de sentir-se poc eficaç en la realització de determinades activitats (sobretot les individuals); el prejudici-molt universitari, per cert-que no és correcte demanar ajuda a altres quan un es troba amb dificultats, i que per tant, quan aquestes apareixien en la realització d'alguna activitat, el fracàs era possible. En canvi, no hem constatat en aquesta experiència reticències a mostrar interès personal que tinguessin com a origen la creença que un no disposava de coneixements, habilitats, trajectòria acadèmica, etc. per sentir-se capaç de dur a terme suficientment les tasques proposades. 


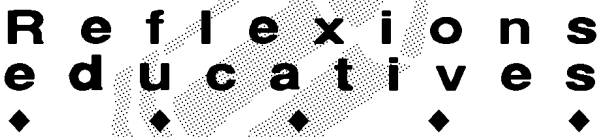

2. L'alumne ha de poder fer seus els objectius, els motius i la utilitat de les activitats d'aprenentatge que se li proposen.

La implicació afectiva de l'estudiant en qualsevol activitat d'aprenentatge depèn també del fet que ell pugui considerar com a propis molts dels supòsits que el professor té prèviament clars pel que fa als continguts objecte d'aprenentatge, als resultats esperats, als processos cognitius reclamats, als criteris d'èxit que avaluen positivament els aprenentatges, o altres (la implicació podria dependre de l'oferta externa de premis, càstigs, amenaces, promeses, etc., però aquest no és l'enfocament en què ens movem).

Molt sovint a l'estudiant no li és fàcil compartir i fer pròpies aquestes condicions $\mathrm{i}$ característiques amb què els professors revesteixen les tasques d'aprenentatge, o perquè no s'expliciten suficientment, o perquè, tot i ser més o menys conegudes, són lluny inicialment dels seus propis objectius i motius, o perquè hi ha molta malfiança en les relacions mútues. Només en el cas que l'alumne manifesti una forta dependència emocional en- vers el professor o una fe cega en la bondat de qualsevol activitat que aquest pugui decidir -com acostuma a passar en etapes primeres de l'escolaritat- és possible la renúncia a l'experiència emocional de l'autonomia personal davant de les tasques escolars. El més normal, però, és que l'estudiant es plantegi sovint quins són els motius que se suposa que hi ha per fer les activitats que se li proposen, quins guanys es poden assolir en fer-les bé, la utilitat que poden tenir per a un futur immediat 0 per a més endavant.

La fragilitat i delicadesa d'aquest procés d'arribar a coincidir en les representacions que tenen alumnes $i$ professor sobre què s'ha de fer, com i per què, obliga a dotar-se de més recursos o ajudes per convertir-lo en més real.

En l'experiència a la qual ens referim hem utilitzat dos instruments intencionalment pensats perquè l'estudiant pogués identificar suficientment les intencions del professor i elaborar en el possible una representació compartida del contingut i les tasques: la guia de treball de cada mòdul de l'assignatura i les orientacions per fer les activitats.

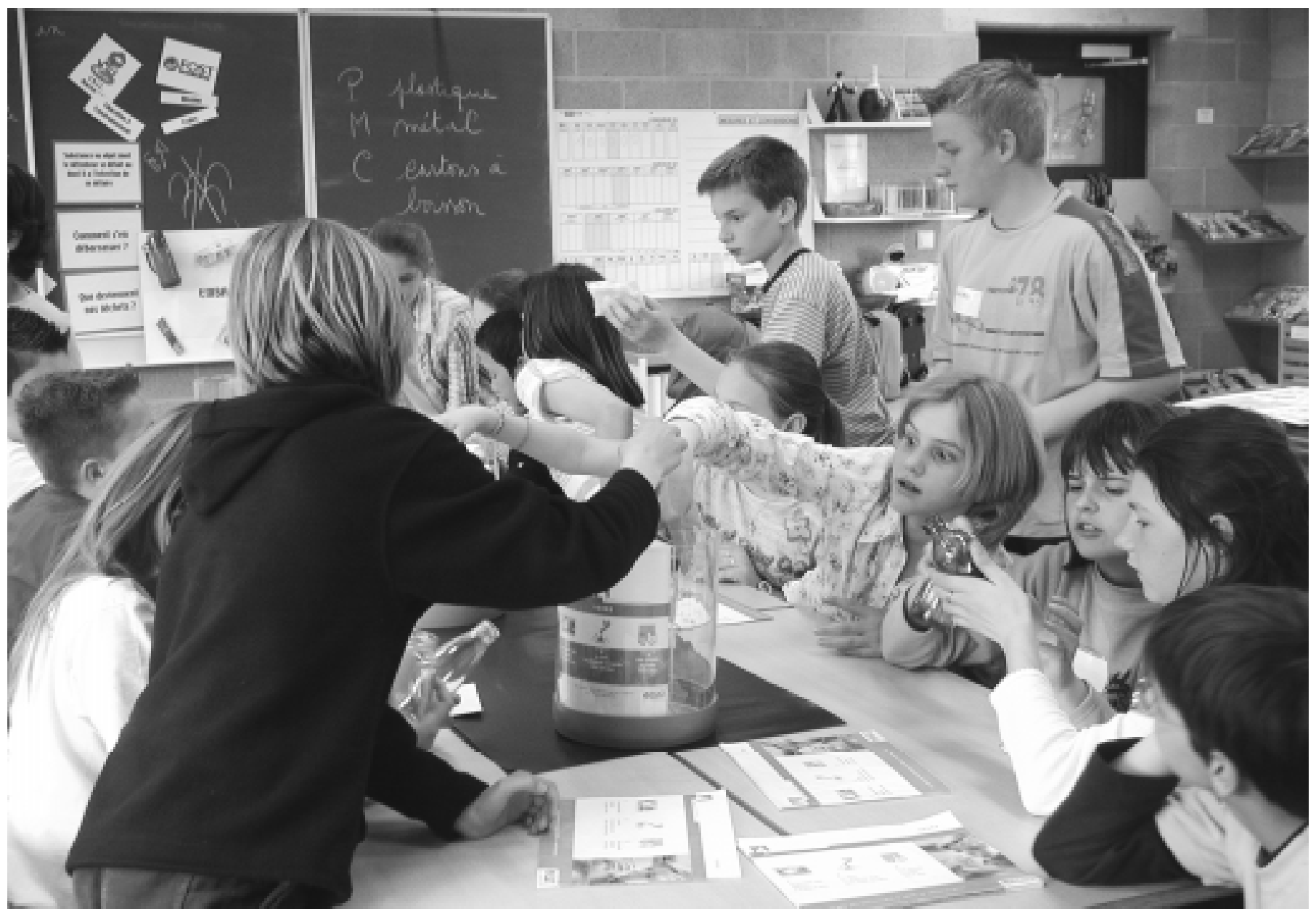




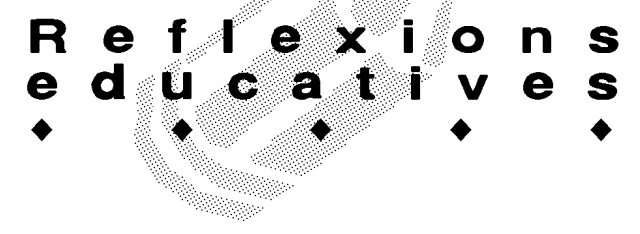

La Guia de treball del mòdul, elaborada curosament pel professor, explicitava informació detallada sobre els següents aspectes:

- El lloc que ocupaven els continguts del mòdul en el conjunt de l'assignatura i en relació amb altres continguts apresos i el valor que es pressuposava a aquests continguts per a la formació de l'estudiant.

- Els objectius que calia prioritzar i la proposta de continguts per assolir-los.

- L'estratègia metodològica que se seguiria per al treball del mòdul i la justificació dels criteris metodològics que el presidirien.

- El calendari de treball amb la planificació setmanal de les tasques.

- La relació de les activitats considerades obligatòries per fer individualment o en equip.

- Els instruments i formes d'avaluació que es farien servir en aquell mòdul.

Cada una de les guies es presentava i comentava amb cert detall en la primera sessió del mòdul, de manera que des del primer dia l'estudiant tindria a l'abast la màxima informació sobre el que el professor esperava. Amb tot, els estudiants no han atorgat en els qüestionaris finals un gran valor a aquestes sessions inicials en comparació amb altres (mitjana: 3,68, sobre 5; desviació: 0,63 ), si bé han reconegut que les guies els havien servit per afavorir els aprenentatges (mitjana: 4,11, sobre 5 , desviació: 0,62). La dada ens ha fet pensar que potser caldria diferenciar més aquest tipus de sessions, o que s'hauria de fer més referència a aquesta sessió marc mentre es desenvolupava el mòdul, o que la presentació inicial no hauria de consistir en una explicitació dels pensaments i intencions només del professor.

Les Orientacions per a la realització de l'activitat explicitaven per a totes i cada una de les activitats les principals condicions a tenir en compte per a la seva realització i valoració positiva. Concretament, s'especificava el següent:

- Els productes a elaborar (informes, quadres, mapes conceptuals, missatges a fòrums, resums $i$ síntesis de lectures, recull de dades observades, taules de valoració) i si aquests productes seguirien algun tipus d'estructura textual determinada.

- El format organitzatiu de l'activitat, individual o en equip.

- Els materials aconsellats que servien per a la realització més profitosa de l'activitat.

- La previsió del temps necessari per a la preparació de l'activitat i per a la seva realització, i l'extensió màxima del producte a presentar.

- Alguna indicació, si s'esqueia, sobre l'ordre dels passos a fer per elaborar l'activitat.
- La menció d'aspectes fonamentals que no haurien de passar per alt.

- Els criteris d'avaluació que presidien la realització de l'activitat, que serien al mateix temps els que es farien servir en el moment de valorar-la definitivament.

Sens dubte, guies i orientacions com aquestes donen més seguretat a l'alumne i li eviten sentiments negatius que apareixen, per exemple, quan un no sap si la seva feina s'ajusta al que es demana, o quan ha de planificar en excés processos poc experimentats, o si tem que apareixeran dubtes que no sabrà solucionar i que comportaran una sensació de no sentir-se bé amb ell mateix, 0 altres semblants.

Ara bé, optar per fer servir instruments com aquests, que semblen pautar excessivament el treball de l'alumne, comporta algun risc, que amb l'experiència portada a terme hem pogut detectar i objectivar més. Pensem que compartir representacions sobre els continguts i les tasques d'aprenentatge ha de significar sobretot que l'alumne arribi a integrar els motius $i$ condicions dels aprenentatges que el professor ha explicitat en l'entramat dels seus propis objectius, i no al revés. No pot ser que l'alumne interpreti que les guies i orientacions donades li estan marcant l'únic camí possible a seguir mentre aprèn; no pot ser que conclogui que allò més valuós a fer és complir al més fidelment possible el que el professor vol. Sembla que molts alumnes -ni que siguin adults - pretenen això, però l'experiència afectivament més positiva consisteix a arribar a sentir tot el contrari, a esdevenir un alumne cada cop més autònom i responsable en la conducció del propi aprenentatge. Les conseqüències emocionals $i$ afectives de l'experiència d'autonomia són molt més profitoses per a l'alumne i, també, per al professor, que quan es conrea la dependència.

Tot i creure que no és fàcil trencar amb inèrcies potser llargament induïdes, considerem que calen mesures que ajudin l'alumne a gaudir de l'experiència d'autonomia quan duu a terme, precisament, unes activitats que el professor no pot deixar d'orientar si pretén facilitar els aprenentatges.

Hem constatat, en aquest sentit, l'eficàcia de dos tipus d'actuacions. Per una banda, aprofitar qualsevol ocasió per estimular la presa de consciència per part de tothom de com es viuen els fenòmens de dependènciaautonomia davant de situacions determinades de la vida de l'aula. Per l'altra banda, procurar no detallar en excés, en les guies i orientacions, com ha de fer el treball l'estudiant; és a dir, deixar prou oberta la possibilitat que l'alumne decideixi no tant què ha de fer o per què -que això competiria principalment al professor-, 


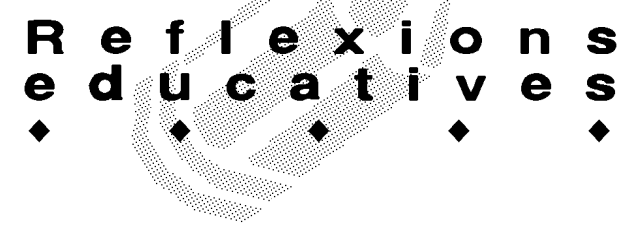

sinó les maneres concretes de dur a terme el seu treball.

Es tracta d'actuacions per al foment de l'autonomia i de l'assumpció del control i regulació dels aprenentatges per part dels alumnes, que entenem que caldria treballar ja des dels parvularis.

\section{L'activació d'emocions i afectes positius a l'aula no depèn només de l'aplicació de determinats recursos}

La vida de l'aula no és mai emocionalment asèptica. En tot cas, quan el professor prepara activitats que connectin amb els interessos dels alumnes o els facilita orientacions i guies perquè aquests es representin i comparteixin bé els continguts $i$ tasques (les dues condicions que hem considerat en aquest article com a decisives per a una major implicació afectiva en l'aprenentatge), el que fa, simplement, és tractar d'augmentar la disposició de l'alumne, la seva dedicació, el valor atorgat, l'estima envers la feina escolar. Però els sentiments, els afectes i les emocions ja hi són presents, perquè els participants de la vida de l'aula són persones que no poden deixar aparcades per una estona aquestes realitats psicològiques. És, per tant, en la inevitable interacció entre els uns i els altres com es generen, es modifiquen, es converteixen en positius o negatius els afectes i les emocions, que no es poden amagar.

Diem això perquè l'experiència acadèmica a la qual ens estem referint també ens ha fet prendre major consciència de les característiques d'una interacció a l'aula positivament recreadora o potenciadora d'afectes, sentiments i emocions positius dels estudiants envers els aprenentatges.

Algunes conclusions a les quals hem arribat, perquè ho hem recollit directament en els qüestionaris d'avaluació final de l'experiència, o perquè ho hem interpretat a partir dels comportaments dels estudiants, són les següents:

- El professor, si vol connectar les activitats d'aprenentatge amb els interessos vertaders dels estudiants, ha d'intentar conèixer-los de la manera més objectiva possible, i no només suposar-los. Les tutories individuals i de grup, les propostes d'autoavaluació, la demanda explícita que siguin ells mateixos els qui formulin els objectius a assolir, són alguns dels recursos que ens han permès apropar-nos al coneixement dels interessos dels estudiants en determinats moments de la seva trajectòria.

- Tal com s'ha dit abans, la percepció per part de l'alumne que el professor està igual d'implicat com ell mateix en la salvaguarda de la seva imatge positiva és potser la clau per a viure sentiments, emocions i afectes positius. L'alumne necessita oir fórmules d'acompanyament sincer per part del professor, necessita veure actuacions clares de compromís i complicitat en els seus èxits, necessita rebre disponibilitat i ajudes per evitar fracassos. En canvi, qualsevol sospita que el professor no està raonablement a favor teu és viscuda per l'alumne com un motiu per al desafecte.

Hem conclòs, arran de l'experiència, que la força afectiva de comportaments de disponibilitat, ajuda, apropament, complicitat..., es troba en la continuïtat i no en la desmesura.

- Els afectes, les emocions, els sentiments es contagien. Des de sempre, l'alumne -sobretot, l'alumne adult- busca en els seus professors evidències de com viuen afectivament i emocionalment la professió, per si això el pot ajudar a redescobrir-se cada dia en el que fan, per què ho fan, com ho fan.

En el decurs de l'experiència hem après a exterioritzar més tranquil-lament les emocions que com a professor s'experimenten, per exemple, quan t'afanyes a posar el coneixement més a l'abast del qui t'escolta, quan veus que els estudiants et presten gratuïtament molta atenció, quan t'adones que hi ha dificultats importants per fer-te entendre, quan descobreixes que alguna intervenció d'algun alumne t'ha permès aclarir algun punt fosc, quan et sembla que estàs explicant coses que no havies dit mai, com si estiguessis creant coneixement nou en aquell precís moment, quan tems que algú quedi a mitges tintes, etc. Es pot pensar que aquesta exteriorització tranquil.la de sentiments, afectes i emocions, sense cap altra restricció que la que imposa el respecte que es mereixen les persones que t'acompanyen, pot servir-los com a font d'informació i de contagi per interpretar i regular les seves pròpies emocions, sentiments i afectes a l'aula.

\section{Bibliografia consultada}

MIRAS, M. Afectos, emociones, atribuciones y expectativas: el sentido del aprendizaje escolar. A C. Coll, J. Palacios, A. Marchesi (comp.): Desarrollo psicológico y educación. 2 Psicologia de la educación escolar. Alianza Editorial (2a edició). Madrid. 2001. Pàg. 309-329.

VALLS, E. Propostes per a una construcció guiada del coneixement en l'educació superior. Ponència presentada a la Jornada d'Innovació Docent, organitzada per la Facultat de Ciències de l'Educació i Psicologia de la URV. Tarragona, 47-2005 (no publicada).

VALLS, E.; MOLAS, E. La formació psicològica de l'estudiant de Magisteri. Adaptació de les corresponents assignatures a l'EEES. Informe final del projecte d'innovació docent subvencionat per l'ICE de la URV. Tarragona, setembre de 2005. 